-HIGHER-

EDUCATION

-POLICY-

Editorial

\title{
Higher Education Policy: Celebrating 25 Years
}

Higher Education Policy (2013) 26, 1-4. doi:10.1057/hep.2012.30

\section{Years}

On the occasion of the 20th birthday of Higher Education Policy, I hesitantly suggested the journal's maturity (Huisman, 2008). Hesitantly, first, for at the same time, the International Association of Universities (IAU) was celebrating 60 years of existence and I did not want to raise the suspicion that the Association was close to retirement. Second, I anticipated that I would need another metaphor for the celebration of the 25th anniversary of the journal. Having set the stage with a certain level of 'maturity' 5 years ago, I am tempted to go now with 'sustained maturity'.

In the past 5 years, another 137 papers and prefaces were published, adding to the 656 papers that appeared in the first two decades. The papers show continued diversity in terms of the topics addressed - ranging from gender issues and internationalisation to research careers, the geographical focus and background of the authors, and the research designs and methods. Later this year, I will analyse the contents of the contributions of the past 5 years and compare this with the past. Here I take the opportunity to look forward and announce a couple of important changes.

\section{Journal Quality}

Journals are - and should be - judged on the quality of the papers appearing in it, against the background of the journal's objectives and mission. Journals maintain academic and professional standards and peer review processes have an important role in these processes. Such processes do not guarantee, however, that all contributions to a journal are of equal quality, if only for the fact that readers value papers differently. Some contributions have particularly emphasised their relevance for policy and practice, whereas others were much stronger in terms of the academic conceptual-theoretical relevance. Quality is - despite journal and professional standards - ultimately in the eye of the beholder.

Whereas relevance for policy and practice is often difficult to measure, academic relevance lends itself - relatively speaking - easily for measurement through bibliometric indicators. If scholars make use of a particular idea or 
2

finding in a published article, one can assume that that article has 'quality'. At the operational level, the quality is often measured by looking at citations of an article: the more an article is cited, the higher its quality (and - as a consequence - the higher the quality of the journal, but see Oswald, 2007 for an interesting reflection on the reliability of journal rankings, see also Weingart, 2005 on the darker sides of bibliometrics). With the rise of Internet technology, citation counts and patterns are readily available through, e.g., Scopus (www.scopus.com) and Google Scholar (http://scholar.google.co.uk). One of the most important and accepted impact factors is produced by Thomson Reuters (http://thomsonreuters.com). The organisation annually provides impact factors for a given set of journals by discipline and thus yields some insight into the journals' prestige (and quality) to researchers, librarians and university managers. I am thrilled to announce that Thomson Reuters has selected Higher Education Policy for inclusion in the Social Science Citation Index and the Journal Citation Reports. This is a clear sign of the confidence put in the journal that it meets Thomson Reuters' quality requirements. From next year on, readers and contributors will have insight in the journal's standing in relation to other (higher) education journals.

\section{Changing the Editorial Board}

A few years after taking over the editorship, I installed a new board of editorial advisors and appointed members for 3 years. That period ended last year and in light of the changing topics addressed in the journal and the need for a diverse membership of the board, I thought it appropriate to make a couple of changes. First, I wanted to sustain the active contribution of the board members and hence suggested to change the name of the Editorial Advisory Board into Editorial Board. Second, I am very pleased to inform you that the following persons have accepted to be member (initially for a 3-year period) of the board: Hugo Horta (Technical University Porto, Portugal), Georg Krücken (University of Kassel, Germany), Liudvika Leišytė (University of Twente, the Netherlands), Christopher Morphew (University of Iowa, United States) and Bjørn Stensaker (University of Oslo). At the same time, we say goodbye to a number of board members. I am grateful to Rollin Kent (National Autonomous University of Mexico), Jos-Gines Mora (University Polytechnic Valencia, Spain), Louis Levy-Garboua (University of Paris I, France) and Ulrich Teichler (University of Kassel, Germany) for their contributions to the journal. Especially, the latter merits a big thanks for he has been on the board since the journal's inception in 1988. As a board member, he has contributed tremendously to the journal's maturation, but has contributed in many other ways, for example, as a very reliable reviewer and as 
a productive contributor - in fact the most productive contributor so far with nine articles in 20 years.

\section{Online Submission and Advance Online Publishing}

Advance Online Publishing system has been in place since May 2012, which means that accepted and proofed papers are available online ahead of print. Subscribers to the journal will have early access to papers that previously were in a queue, waiting to be published in the paper version. Another advantage is that authors will have their papers available to the broader public and, as such, earlier exposure of their work and 'proof' of publication. The latter becomes increasingly important in appraisals and promotion processes.

In close cooperation with the publisher, we are currently working to get a system of online submission in place. This would make the submission and review process more transparent and efficient. As soon as the system is live, we will announce this on the journal's website. The launch of online submission does not affect the papers that have already been submitted and are under review or revised with the intention of resubmission.

\section{Special Anniversary Issue}

To celebrate the journal's anniversary, the last issue of this year (2013) will be a special issue. The theme will be From the Vaults: Revisiting, Revising and Reflecting on Higher Education Policy Research. Through the IAU e-bulletin and the journal website, contributors have been invited to select a seminal article from the Higher Education Policy archives and reflect on that paper or on a couple of papers on the same theme. I hope to see interesting contemporary reflections on - just to mention a couple of examples - Trow's (1996) paper on trust, Gornitzka and Maassen's (2000) paper on state steering or Bray and Kwo's (2003) paper on higher education in small territories.

Jeroen Huisman

University of Bath, United Kingdom

\section{References}

Bray, M. and Kwo, O. (2003) 'Higher education in small territories: Political transition and development in Macau', Higher Education Policy 16(4): 413-432.

Gornitzka, $\AA$. and Maassen, P. (2000) 'Hybrid steering approaches with respect to European higher education', Higher Education Policy 13(3): 267-268. 
许 Editorial

4

Huisman, J. (2008) 'Higher education policy: The evolution of a journal', Higher Education Policy 21(2): 265-274.

Oswald, A.J. (2007) 'An examination of the reliability of prestigious scholarly journals: Evidence and implications for decision-makers', Economica 74(293): 21-31.

Trow, M. (1996) 'Trust, markets and accountability in higher education: A comparative perspective', Higher Education Policy 9(4): 309-324.

Weingart, P. (2005) 'Impact of bibliometrics upon the science system: Inadvertent consequences?', Scientometrics 62(1): 117-131. 